\title{
Why People Live in Flood-Prone Areas in Akuressa, Sri Lanka
}

\author{
Johan Askman $^{1} \cdot$ Olof Nilsson $^{1} \cdot$ Per Becker $^{1}$
}

Published online: 27 March 2018

(C) The Author(s) 2018

\begin{abstract}
To investigate why people live in areas at high risk of floods, a qualitative case study was carried out in the areas around Akuressa, in southwest Sri Lanka. Data collection consisted mainly of semistructured interviews with local residents and government officials. The purpose was to study why people live in areas at high risk of floods, by looking beyond the purely physical aspects of living with hazards and exploring the underlying social factors. Four main factors were identified: an overall good living situation; a sense of place; difficulties relocating; and being well-adapted to the situation. The analysis also examined whether government officials shared the views of local residents. The findings highlighted both areas of consensus and discrepancies related to risk awareness, and the efficiency of risk reduction measures that had been implemented by the government. The case study identified and explored underlying social factors, such as risk normalization, risk trade-offs, and push-and-pull processes, which seem to influence the decision to live in a high-risk area.
\end{abstract}

Keywords Flood risk - Risk awareness - Risk perception $\cdot$ Sri Lanka

\section{Introduction}

Globally, floods are the most common disaster (CRED 2016), and while they can impact just a few households, they can also affect whole communities or entire provinces.

\footnotetext{
Per Becker

per.becker@risk.lth.se

1 Division of Risk Management and Societal Safety, Lund University, 22100 Lund, Sweden
}

At the same time, in many contexts, they are necessary for biodiversity, wetlands, and agriculture, all of which makes flood risk management very complex (Becker 2014). Disasters cannot be understood merely as the hazards that trigger them. They must also be seen in terms of their consequences for something valuable that is vulnerable to their impact (Wisner et al. 2003). Different individuals and groups are affected differently, and their ability to cope with the events differs, depending on a range of factors, such as income, living situation, gender, ethnicity, and age (Hearn Morrow 1999; Wisner et al. 2003). This differentiated approach to understanding disasters has proven central for disaster risk management, as it expands the options for risk reduction activities. Rather than only focusing on controlling nature, disaster risk management can extend to preparedness and nonstructural mitigation (Coppola 2011), as well as addressing root causes such as structural injustice (Wisner et al. 2003).

A fundamental aspect of flood risk is exposure. Scholars have pointed out that disasters are the result of people living in places they are insufficiently adapted to (White 1945; Kates 1976; Burton et al. 1978). Although this perspective has been criticized for downplaying the role of societal circumstances and historical processes (O'Keefe et al. 1976; Hewitt 1983), it is crucial to understand why people live in flood-prone areas (Wisner et al. 2003) to inform the design and implementation of risk reduction activities that involve community members.

In Sri Lanka, floods are the most common type of disaster and flood risk is escalating due to deforestation, improper land use, and growing populations (Ministry of Disaster Management Sri Lanka 2012). The majority of floods are caused by overflowing rivers during the two monsoon seasons. The May 2003 floods were the worst disaster triggered by natural hazards the country had 
experienced in over 50 years (Zubair 2004), before the 2004 tsunami. The Nilwala River in southwest Sri Lanka is among the most flood-prone rivers in the country and causes floods of different degrees almost every year (Ministry of Disaster Management Sri Lanka 2012). It provides an interesting case study for why people live in flood-prone areas. The purpose of this study is to further our understanding of why people live in flood-prone areas, and specifically of why people live in flood-prone areas around Akuressa, Sri Lanka.

\section{The Study Area}

Akuressa is a town along the Nilwala River in the District of Matara (Fig. 1), functioning as a commercial hub with a market where many of the farmers in the region travel to sell tea, rubber, spices, and other foods. The climate in the region is suitable for cultivating various types of crops and spices, making land expensive and high-in-demand. Over 50,000 people live in the town and surrounding areas, a majority of which are estimated to live in rural areas (Ministry of Policy Planning and Economic Affairs 2012). The topography is flat with many people living in floodprone areas, including all of the respondents who were selected based on them being flooded more or less every year.
The Nilwala River is approximately $70 \mathrm{~km}$ long with a total catchment area of $970 \mathrm{~km}^{2}$. The average annual rainfall in the catchment ranges from 1650 to $4000 \mathrm{~mm}$ depending on location, with the northern hilly areas being exposed to more rain than the lowland coastal areas. The amount of water in the river differs considerably due to two annual monsoon seasons with peaks in November and May, when flows more than triple compared to the dry periods (Sooriyabandara 2016). The severity of floods varies depending on the amount and intensity of rainfall, but river floods occurred at least once in $80 \%$ of the years between 1980 and 2011 (Fig. 2), with floods reoccurring more or less every year since then (Sooriyabandara 2016). Major floods are also common, with up to eight such floods per decade (Fig. 2). However, the May 2003 floods stick out with $80 \%$ higher flood level than the second most severe floods between 1980 and 2011 (Fig. 2). No early warnings were issued as the path of the cyclone was far from Sri Lanka (Zubair 2004). These floods were catastrophic in Akuressa and most respondents referred to them during the interviews.

Attempts to mitigate floods were conducted in the 1980s in a project often referred to as the Nilwala Project. It consisted of a three-step scheme where step one and step two involved the construction and completion of embankments and drainage systems along the river. The third step involving the construction of a dam was cancelled and
Fig. 1 The location of Akuressa in Matara District in Sri lanka
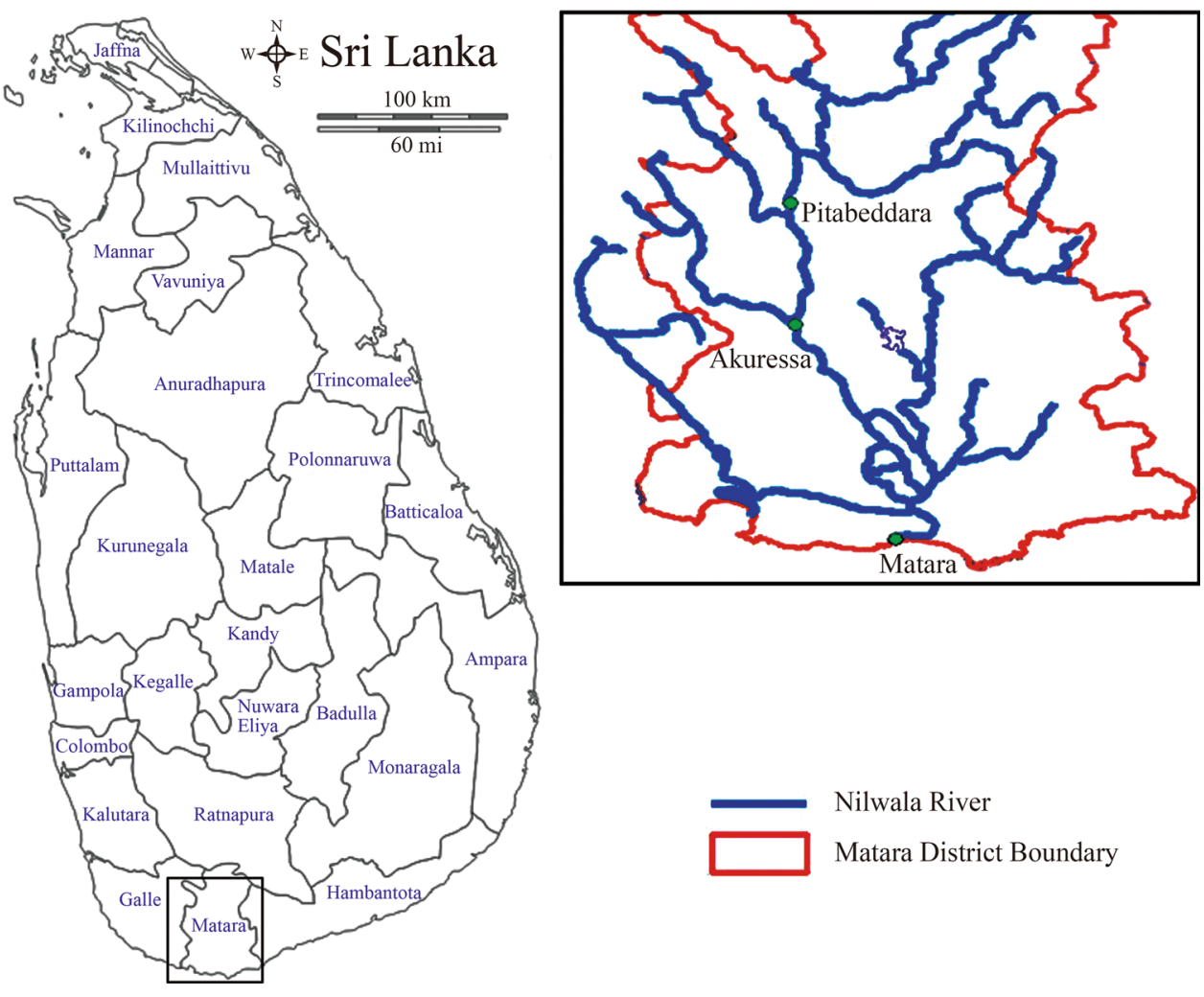
Fig. 2 Nilwala River flood water levels from 1980-2011 at Pitabeddara, $15 \mathrm{~km}$ upstream of Akuressa. The red solid line indicates the water level where floods occur (Ministry of Disaster Management Sri Lanka 2012) and the dashed line on 4.5 feet marks the threshold for major floods (Sooriyabandara 2016)

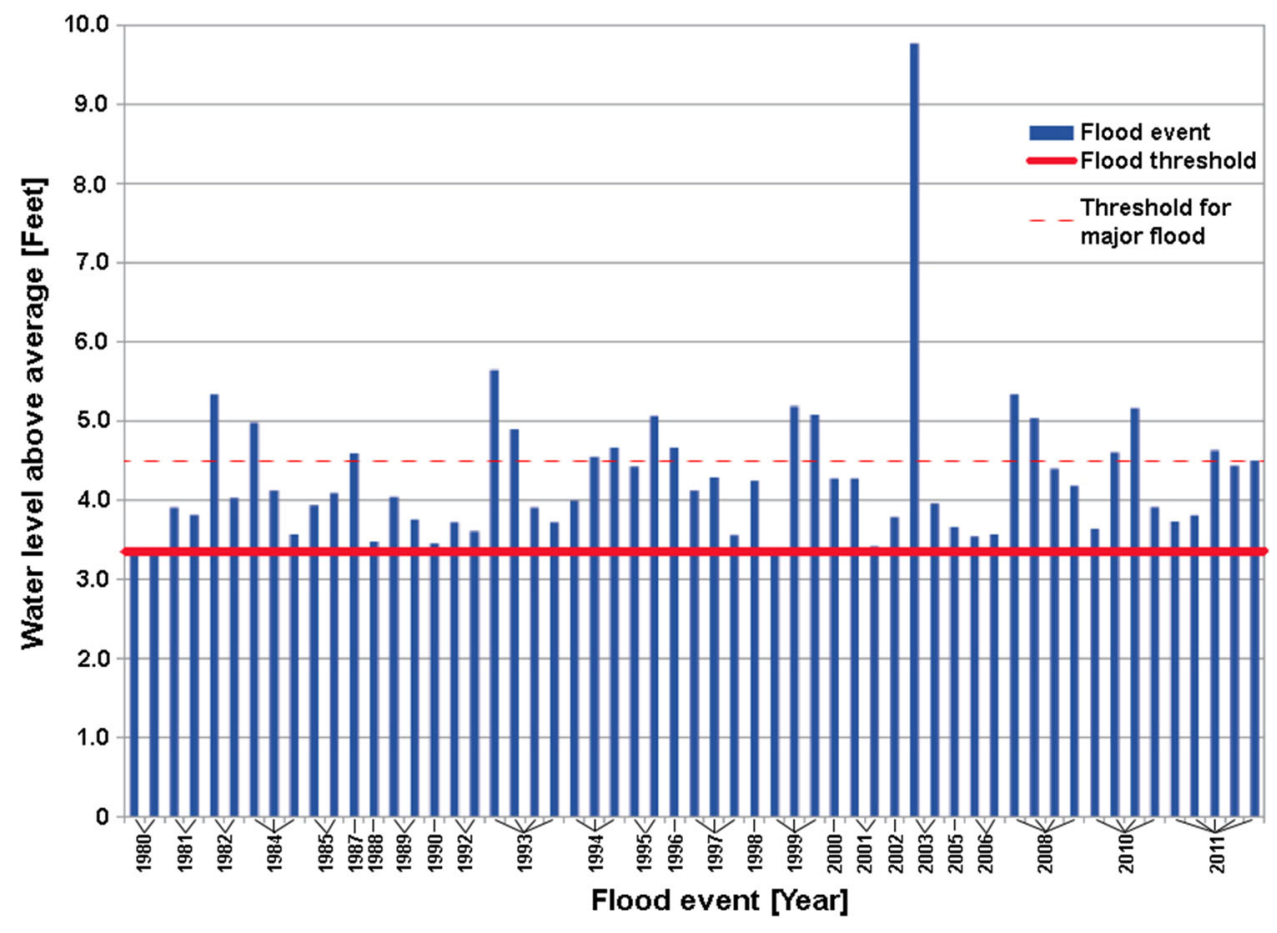

never completed. These efforts still provide protection for some areas in the district but far from all (Sooriyabandara 2016), including large areas around Akuressa.

\section{Conceptual Framework}

Risk can be described as a combination of likelihood and consequence. By multiplying the two factors, the risk of a specific hazard, in a specific context, can be calculated. These two factors can be described both qualitatively and quantitatively, and in several ways depending on the aim and context (Coppola 2011). However, risk consists of more than just its technical aspects, and its research should include the subjective values that serve a purpose in different situations. For example, Renn (1998), Slovic (2001), and Coppola (2011) emphasize the importance of risk awareness and risk perception.

Risk awareness can be described as the knowledge and consciousness of the risks associated with a hazard (Raaijmakers et al. 2008; Luìs et al. 2016). A lack of awareness regarding a risk is likely to result in a lack of preparedness (Scolobig et al. 2012). A person who is unaware that he/she is at risk, is unlikely to take any risk reduction actions. When individuals or communities experience a hazardous event, their awareness of the risks associated with this hazard tends to increase (Scolobig et al. 2012). When a hazard does not affect an area for a long period of time, awareness is likely to decline (Raaijmakers et al. 2008). Within the scope of this article, risk awareness is defined as the awareness of the likelihood and physical consequences associated with a hazard.

Values and feelings contribute to the more subjective concept of risk perception. Studies have shown that risk is often perceived differently than its statistical history suggests, and can differ between individuals. The reasons for this are important to consider when trying to understand the decisions made by those exposed to hazards (Coppola 2011). How a risk is perceived is, to some extent, determined simply by the general level of knowledge of the risk. Other factors that have proven to be of importance are: whether the risk exposure is voluntary or not (Sjöberg 2000); whether the risk is new or old (Sjöberg 2000); whether the impact is immediate or delayed; whether the hazard is controllable or not; whether there are many fatalities as the result of one event or few fatalities from many events (Smith 2013); and the uncertainty attributed to the risk (Coppola 2011). Differences in risk perception between individuals and groups mean that it is crucial to consider such factors and gain an understanding of the individuals and groups exposed. Otherwise, the process of disaster risk management is likely to result in efforts that do not correspond to the needs expressed by those affected (Coppola 2011).

The strictly technical way of studying disasters and their consequences is heavily focused on the physical events as such. However, when a destructive event such as a flood occurs in an uninhabited area, it is not considered a disaster and can even be considered beneficial (Wisner et al. 2003; McEntire 2005). This has called attention to the fact that 
human involvement, or the involvement of what humans value, is a vital component in what constitutes a disaster. The extent of adverse effects caused by natural hazards is highly dependent on the vulnerability of the entity affected (Wisner et al. 2003).

The concept of vulnerability is not just a function of the level of exposure to a hazard, but also extends to the capacity of the individual, community, system, or other entity to anticipate, cope with, and recover from the impact of the event (Turner II et al. 2003; Wisner et al. 2003). When studying vulnerability, one must therefore consider a range of physical, environmental, social, cultural, political, and economic factors (Becker 2014). Key aspects that influence vulnerability include the financial situation, occupation, gender, age, health, and ethnicity of those affected. Poverty is often considered one of the biggest contributors to vulnerability. Although there is no direct connection, poverty and vulnerability are often highly correlated, and poor people tend to suffer the most from disasters (Wisner et al. 2003). It is also important to note that vulnerability is dynamic. The level of vulnerability can change over time, due to both changes in local conditions, and the ability to cope with a hazard. Furthermore, the level of vulnerability can result from effects that only become visible long after the initial event, adding yet another dimension to the concept's dynamic nature. Consequently, vulnerability is a very complex concept that is not easily reduced to numeric measurements, making it difficult to quantify (Wisner et al. 2003; Adger 2006).

\section{Methodology}

Qualitative case study research was a suitable methodology for the purpose of this study (Yin 2002). Data were collected using qualitative, semistructured interviews, conducted within broad guidelines that included predetermined and open-ended questions that encouraged respondents to elaborate freely on the topic (Bernard 2006; Longhurst 2016). Data were also collected through observationvaluable information about the local context was used to adapt and improve the interviews.

Interviews were structured into three phases (Höst et al. 2006): (1) a brief conversation about Akuressa and life in general there; (2) general questions about the respondent's age, occupation, activities outside work, and so on; and (3) a more in-depth dialogue concerning the reasons for and the dangers associated with living in Akuressa. With one exception, all of the interviews were recorded, with the respondents' permission, to facilitate further analysis. All respondents spoke Sinhalese, and an interpreter was provided by the local Red Cross branch in Matara, the regional capital. The interpreter had previous experience in disaster management field work and had previously worked as an interpreter, but had no formal education concerning flood risk or development. Even though it took time and effort, the collaboration transitioned from interpreting answers towards translating them. However, all interviews are believed to be mostly interpreted rather than translated. When a message is mediated several times between three different parties, and especially from one language to another, certain information and some details can disappear or become misleading (Freed 1988). We are still confident that the results in total provide enough to make an important contribution.

Interviews were conducted in August and September 2016, in areas in and around the town of Akuressa. These areas were selected based on the extent of previous floods, described by the government's Disaster Management Center in Matara, and are situated along the Nilwala River, which causes floods most years (Sooriyabandara 2016). Interviewees comprised 45 local residents (28 male and 17 female) and six government officials. The overrepresentation of male respondents $(62 \%)$ is explained by the fact that when a male was present when an interview was conducted, they often considered themselves to be the most suitable person to answer the questions, making it difficult to achieve an ideal distribution. Similar cultural expectations skewed the age distribution (Table 1). Nevertheless, as this was a qualitative study, while complete gender and age balance are desirable, they are not required for analytically significant results.

The study targeted rural, semirural, and urban settings, in order to be able to analyze similarities and differences in responses. Respondents were selected by identifying floodprone houses while walking in the areas along the river. The first 10 interviews were held in the most rural setting. At the end of the study, this rural area was revisited to ensure that what had been learned during the subsequent interviews had not affected the outcome or quality of these initial interviews. This was done by comparing the results

Table 1 Distribution of gender and age of the respondents, and their urban-rural residential status in the Akuressa study area of Sri Lanka

\begin{tabular}{lll}
\hline Age & Female/male & Urban/semirural/rural \\
\hline $19-29$ & $3 / 2$ & $2 / 2 / 1$ \\
$30-39$ & $4 / 3$ & $3 / 2 / 2$ \\
$40-49$ & $2 / 9$ & $4 / 1 / 6$ \\
$50-59$ & $2 / 4$ & $0 / 2 / 4$ \\
$60-69$ & $3 / 7$ & $2 / 3 / 5$ \\
$70-79$ & $2 / 3$ & $0 / 2 / 3$ \\
$80-$ & $1 / 0$ & $0 / 0 / 1$ \\
\hline
\end{tabular}

Total $17 / 28=45$ and $11 / 12 / 22=45$ 
from the first and last interviews, and at the same time checking for theoretical saturation. No significant differences were identified. The six interviews with government officials (five of which were recorded) were held with highlevel representatives of the District Planning Department, the Disaster Management Center, the District Irrigation Department, the Akuressa Divisional Secretariat, and the Athuraliya Divisional Secretariat (bordering Akuressa). All of these bodies were deemed central for the management of floods in the study area.

The recorded interviews were transcribed (notes were taken during the one unrecorded interview) and analyzed in three interdependent steps: (1) coding sentences or paragraphs; (2) forming concepts by aggregating related codes; and (3) constructing categories by connecting related concepts (Charmaz 2006). The process of coding started as soon as the first interviews were transcribed. Coding and data analysis continued in parallel with the interviews in order to identify trends and concepts of interest that could be explored further in later interviews. Data analysis was performed by NVIVO software. ${ }^{1}$

\section{Results}

Results are presented in two sections: first responses from local residents, followed by responses from government officials. They are structured into the categories that emerged from the analysis. First concerning why people live in flood-prone areas (Sects. 5.1, 5.2), then concerning preparedness and response activities (Sect. 5.3). As the raw data led to the creation of over 300 codes, the depth of the data presented here is limited to the concepts underlying the categories, while representative quotes are provided as examples of the underlying codes.

\subsection{Local Residents}

Four main categories emerged from the data analysis concerning why people live in flood-prone areas: overall good living situation; sense of place; difficulties relocating; and being well-adapted to the situation.

\subsubsection{Overall Good Living Situation}

Many respondents seemed happy with their overall living situation. Half of the respondents mentioned three or more positive things about living in the area, while more than $80 \%$ mentioned two or fewer negative things. Floods were, by far, the most frequently mentioned downside. The respondents listed 16 benefits (Table 2). The total number

\footnotetext{
${ }^{1}$ https://www.qsrinternational.com/nvivo.
}

of respondents given in Table 2 is above 45 because many respondents mentioned several benefits.

The four most frequently mentioned benefits were: (1) Environment and weather; (2) Cultivation and resources; (3) Public services; and (4) Nice people. Respondents from rural areas emphasized the importance of cultivation to a greater extent than those living in urban areas, while urban residents appreciated their access to public services. There were no significant differences regarding the environment and weather.

Roughly $60 \%$ of the respondents noted the good environment and weather in the valley. The temperatures are considered moderate, not too cold or hot, often with a nice breeze, and the availability of clean water is good compared to other parts of Sri Lanka. Some respondents compared the local environment with the situation in larger cities, describing them as dirty, hot, and noisy.

When compared to other parts of Sri Lanka this is the best place to live in terms of climate I think. It's not too hot and not too cold, very nice temperature year around. (Interview \#6)

Close to $50 \%$ of the respondents noted that the area was suitable for cultivation and provided access to resources. Some, predominantly those living in more rural areas, cultivate crops for their own consumption and/or sale. However, the area also supplies other valuable resources such as coconut, jackfruit, spices, and clean drinking water.

If we lived in an urban area we would have to buy all the things like food supplies, but here we can grow and supply ourselves. We still buy things like fish, salt, and spices in the city but we can supply a lot of things for ourselves here. (Interview \#16)

About $40 \%$ of those interviewed appreciated the easy access to public services and amenities found in Akuressa town. Services include the hospital, schools, shops, the large market, banks, government offices, and the recently upgraded central bus station.

It's close to the road, the town, and the hospital. A lot of people here live on the top of mountains but we live close to the city, those are the good things about living here. At any time, we can easily get to the market or any other place. (Interview \#12)

Around $20 \%$ of those interviewed appreciated the nice people in the community and felt well integrated. Comparisons were made with people living in larger cities, who were considered by some to have a different mentality.

People are good and not aggressive here. They are educated and have sober habits. In the city, there are a 
Table 2 Benefits of living in the current location of the Akuressa area in Sri Lanka

\begin{tabular}{ll}
\hline Mentioned benefit & Number of respondents \\
\hline Environment and weather & 28 \\
Cultivation and resources & 22 \\
Public services & 18 \\
Nice people & 10 \\
Good water supply & 7 \\
Good infrastructure & 5 \\
Quiet and peaceful & 5 \\
Sense of place & 3 \\
Job opportunities & 3 \\
Muslims well integrated & 2 \\
Religious facilities nearby & 1 \\
River nearby & 1 \\
No mosquitos & 1 \\
Nice surroundings & 1 \\
Newly renovated house & 1 \\
Close to family and friends & 1 \\
\hline
\end{tabular}

lot of people with polluted minds, their characters are not so good. (Interview \#8)

\subsubsection{Sense of Place}

Sense of place encompasses a variety of codes and concepts. For example, more than half of the respondents were born in their current place of residence. In many cases, land and housing have been inherited through generations, resulting in a strong connection to the current location. A stated benefit of the current location included being close to family members and relatives, which is also indicative of the concept. In total, $80 \%$ (36 out of 45 ) of the respondents expressed views that were associated with a strong sense of place (Table 3). As several respondents mentioned more than one factor, the total exceeds 36 .

No significant location or gender differences were found between the respondents. Several other responses were thought to indicate or influence a strong sense of place. Some respondents mentioned, for example, that the benefits of their current location were nice people and being part of a well-integrated community. Although these examples are more indirect, it is likely that they also contribute to feeling more connected to the current location. Of those who expressed their unwillingness to relocate, almost half (10 out of 24) mentioned sense of place as one of the major reasons.
Table 3 Responses from the local residents associated with a sense of place in the Akuressa area of Sri Lanka

\begin{tabular}{ll}
\hline Sense of place & $\begin{array}{l}\text { Number of } \\
\text { respondents }\end{array}$ \\
\hline Born in current location & 26 \\
Generational ties & 24 \\
$\begin{array}{l}\text { Close to family and relatives } \\
\quad \text { benefit of current location) }\end{array}$ & 1 \\
Likes the village & 1 \\
$\quad \begin{array}{l}\text { Wants to be close to relatives } \\
\quad(\text { reason not to move) }\end{array}$ & 1 \\
\hline
\end{tabular}

No, I would not like to move, we have been here for generations and I was born here. This is my heritage. (Interview \#39)

\subsubsection{Difficulties Relocating}

One significant reason why the respondents continue to live in the flood-prone areas around Akuressa seems to be the perceived difficulty of moving elsewhere. When asked whether they would consider moving somewhere else, around $40 \%$ were inclined to do so. All respondents in the youngest age group (19-29 years) expressed a positive attitude, the one respondent in the oldest age group (80-89 years) was unenthusiastic, and between 50 and $67 \%$ of the remainder were unwilling. There were no significant differences between urban or semirural areas, with only a slightly greater willingness to move among rural respondents. The majority of female respondents were positive about moving, while the majority of male respondents were negative. Of the around $40 \%$ willing to relocate, over $70 \%$ noted serious difficulties associated with doing so (Table 4).

Age group, gender, and location comparisons revealed interesting differences. The age group comparison showed that no one in the youngest group (19-29 years) expressed concerns about the difficulty of relocation, while all other groups did. A comparison of males and females shows that the most frequently mentioned difficulty among males is financial constraints; however, it is not mentioned by any females. The comparison of urban, semirural, and rural residents showed that urban residents did not state any difficulties related to relocation, unlike rural and semirural residents. The most frequently stated issues were the belief that it would be impossible to find another place, financial constraints, and the belief that it would be impossible to find an equivalent situation in a new location.

We have thought about it [moving] several times but we won't be able to establish a place like this 
Table 4 Difficulties expressed by local residents regarding relocation in the Akuressa area of Sri Lanka

\begin{tabular}{ll}
\hline Difficulties regarding relocation & $\begin{array}{l}\text { Number of } \\
\text { respondents }\end{array}$ \\
\hline Nowhere to go & 6 \\
Financial & 5 \\
No equivalent place to live & 4 \\
Oldest man of the house doesn't & 1 \\
$\quad$ want to move & \\
$\begin{array}{l}\text { Don't know how to look for a } \\
\text { new place }\end{array}$ & 1 \\
\hline
\end{tabular}

somewhere else with this kind of house and these surroundings. (Interview \#16)

\subsubsection{Well-Adapted to the Situation}

The results presented here are based on several factors, including interview responses, field observations, and implicit indications from the respondents. Most respondents appeared to be accustomed to the annual floods and were confident in handling such a situation. It is likely that this is closely connected to the fact that many of them were born in their current location, or have lived there for a long time. When asked how the floods affected them, a frequent response was that they went to stay with friends or family on higher ground for a few days. When the water receded, they returned to their homes, cleaned out the debris and rubbish from the flood, and moved back in. There is a clear sense of inherent knowledge, and it appears that long-term exposure to floods has forced inhabitants to find ways to live with the risk.

Some houses are equipped with an external stairway leading to a habitable roof or a semi-complete second storey. Some respondents with this kind of arrangement stated that they moved to the upper floor when they saw signs of a flood, or used it to store valuables such as furniture during floods.

No, there's no need to worry! If there's a flood we move to the second storey. We will survive there. [...] Normally we open all the doors and windows. If they are closed the pressure of the water can damage them. If they are open, the water can freely come in here and we get no damage. We knew before we came here this area was flood-prone, that's why we built with concrete. [...] We only need to clean. (Interview \#45)

\subsection{Government Officials}

Interviews with government officials revealed a clear consensus in terms of the main reasons why people live in the high-risk areas around Akuressa (Table 5). The same three reasons were given by more than one person: generational ties, financial constraints, and a lack of land, which corresponds well with local residents' views. A selection of quotes is presented below.

In addition, they have their own culture and tradition. They don't like to move from their own land that has been taken from generation to generation. They are used to always living in the same place. (Interview \#47)

They have adapted to the situation. Most people have lived here through the generations, and that is also why they don't want to move to other places, in combination with their ability to protect their valuables [in the event of a flood]. If there is a flood, they rush to a safe place and stay there. But there have been lots of fatalities reported too. In 2003, this whole area was under water. [When there's a flood] the water recedes after a week and then they can start their lives again. They have their own strategies; they know how to protect themselves. (Interview \#49)

\subsection{Risk Awareness of Residents and Officials and their Responses to Flood Events}

This section compares the risk awareness of local residents and government officials in order to identify similarities and differences.

\subsubsection{Preparedness}

Most local residents appear to have a high level of risk awareness, and roughly one-third actively take steps to mitigate, or in other ways manage, the effects of floods (Table 6).

Residents also engaged in preparedness activities without realizing it. A common example is an

Table 5 Government officials' views of why people live in the highrisk areas studied in the Akuressa area of Sri Lanka

\begin{tabular}{ll}
\hline $\begin{array}{l}\text { Reasons why people live in the flood-prone } \\
\text { areas according to government officials }\end{array}$ & $\begin{array}{l}\text { Number of } \\
\text { respondents }\end{array}$ \\
\hline Sense of place & 2 \\
Financial constraints & 2 \\
Lack of land & 2 \\
Local residents are well-adapted & 1 \\
Many benefits of living in the Akuressa area & 1 \\
Government cannot provide alternative location & 1 \\
Not sure & 1 \\
\hline
\end{tabular}


informal, household-level evacuation plan in case of a flood.

Apart from raising the level of the new house we have identified a place in the hills that would be a good place to evacuate to if a big flood happens. We would take our valuables and go there ourselves. (Interview \#8)

I can examine the water level from here and I can tell when there will be a flood and then I buy some supplies from the shops nearby. (Interview \#41)

Government officials suggested a high level of risk awareness among local residents. One stated that many local residents have lived in the same area for generations, and that both the knowledge and strategies to cope with flood events have been passed down through generations. However, others expressed the view that, despite a generally high level of risk awareness, people still acted in ways that did not seem to be in their best interests, due to different underlying reasons such as lack of land or financial constraints. It appears that a high level of awareness does not necessarily lead to a high level of preparedness.

Other than that, people don't have land, because of that they are going to the lowest levels and they are building in these low-lying lands. Naturally these areas are hit when there's a flood, it's low-lying level land and it's going to flood. (Interview \#47)

\subsubsection{Responses to Flood Events}

Thirty respondents identified concrete responses related to flood events. Most are associated with saving lives (Table 7) and correspond to evacuation strategies. Roughly half stated that they evacuated to the homes of friends or

Table 6 Preparedness efforts mentioned by local residents in the Akuressa area of Sri Lanka

\begin{tabular}{ll}
\hline Preparations for floods & Number of respondents \\
\hline Raised level of house & 4 \\
Store rations of food & 3 \\
Monitor river water level & 3 \\
Second storey being built & 3 \\
Sending children to safety & 2 \\
Built second storey & 2 \\
Having money saved up & 2 \\
Phone contact with people upstream & 2 \\
Sandbags & 1 \\
Cooking items & 1 \\
\hline
\end{tabular}

family when they realized that there would be a flood. Other variations were: evacuate to higher ground; evacuate with our valuables to a safer place; and evacuate to the second storey. Concepts of health and property protection consist of "avoiding health issues by staying away from the flood water," and "protecting valuable and/or vulnerable items" respectively.

The analysis of government official replies to questions on flood response highlighted a few interesting aspects. Their priorities seem to closely match those of local residents in most cases. Life safety, and the initiation of an emergency response is most important. An interesting statement, related to a growing problem with crocodiles in the river, highlighted another dimension of the potential consequences of floods.

Due to the crocodile problem, the younger generation cannot swim because no one touches the river. Ten years ago, everyone in this valley could swim. But the crocodile problem is a big issue, now no one touches the water resources. And in this area people don't like to go to the ocean. It's a big problem because now, if there's a big flood, the younger generation cannot swim. The older generation is weak. The generation in between can survive. (Interview \#49)

Another interesting aspect that emerged from the comparison of the views of local residents with those of government officials is a discrepancy regarding where people evacuate to. Government officials stated that a number of safe locations had been established.

The Divisional Secretariat has been divided into 46 local administrative areas. I'm responsible for contacting all of the officers of each local district. There are 46 safe places introduced by me in collaboration with the DMC [Disaster Management Center] in Matara. Just after any hazard [has happened] I have to contact these 46 officers and inform them about an evacuation to the safe place. I also have to initiate immediate action to help and rescue people. [...] [The safe place] should not be prone to floods or any other hazards. Secondly, it should be easily reached,

Table 7 Distribution of concepts in the category "Response to floods" in the Akuressa area of Sri Lanka

\begin{tabular}{ll}
\hline Response to floods & Number of respondents \\
\hline Life safety & 28 \\
Property protection & 4 \\
Health (not emergency) & 2 \\
\hline
\end{tabular}


accessible for the people living in the area. Third, the place should have good facilities and amenities. Good infrastructure. These are the best places. The majority of the safe places in Sri Lanka are schools or temples because these have been built on top of hills and have public toilets. They are usually spacious too. (Interview \#49)

One government official clearly believed that most people used these safe places. However, data collected from local residents suggest that this is not the case. As mentioned above, roughly half of those who mentioned evacuation explicitly stated that they go to stay with friends or family. Although some said that they evacuated to "safe places" without elaborating further, no one specifically stated that they would evacuate to one of the safe places established by the government. One respondent did mention such places, and shed further light on the problems associated with them.

Also, there is a safe place established for the community. When the early warning group detects signs of flooding everyone has to go here. But if a flood happens quickly, a flash flood, we wouldn't have time to go there and that's why we wanted to get a boat. The DMC [Disaster Management Center] have told us that if we don't go to the designated safe place we will not receive any relief or help in case of flood emergencies. But we feel it is risky to go to this safe place, we could die on the way there, so we want to go to our parents' place instead, since it is closer. But if we go there we will not get any help from the government as they only send assessors to this designated safe place to assess damage. (Interview \#4)

\subsubsection{Proposed Improvements}

All local residents (45) suggested improvements to the current situation. Thirty-seven mentioned some form of structural improvement (Table 8), in particular the completion of the Nilwala Project (26 out of 37 respondents). This project started in the 1980s, and consists of a threestep scheme, in which steps one and two involve the construction and completion of embankments and drainage systems along the river. Step three concerns the construction of a dam that was never completed (Sooriyabandara 2016). The second most common suggestion was an improved drainage system (8 out of 37 respondents). Other suggestions included building bridges so that water could flow underneath, establishing a proper irrigation system, and building protective walls and embankments. Nonstructural suggestions included dredging the river, improving maintenance, and reducing pollution levels in the river.

The interviews with the government officials showed a more even distribution of structural and nonstructural suggestions for improvements. Three made both structural and nonstructural suggestions, while one made only structural suggestions and one made only nonstructural suggestions (Table 8). Structural suggestions from government officials included the Nilwala Project, improved drainage and irrigation systems, building houses in safer areas, and renovating flood banks. Nonstructural suggestions included relocating people to safer areas using compensation, dredging the river, improving maintenance policies, and clearer directives on the responsibilities of authorities and educating the local public.

\section{Discussion}

The discussion has four parts, concerning normalization of risk, risk trade-offs, pulling and pushing processes, and a government-community disconnect.

\subsection{Normalization of Risk}

The majority of people interviewed stated that they experience floods annually and, in many cases, several times per year. Consequently, there seems to be a general sense that floods are a part of life. Local residents living with this hazard appear to normalize the risks associated with floods, and consider flooding more of an inconvenience than a disaster. Yet, although local residents demonstrate a high level of risk awareness, in many cases their levels of personal risk perception are low, which could be one of the reasons why people continue to live in flood-prone areas. This could also partly explain why a relatively small percentage of respondents were actively engaged in explicit preparedness actions, despite the high level of risk awareness. Risk awareness is a prerequisite for increased risk perception and preparedness. If you are unaware that you are at risk, you are unlikely to take any risk-reduction actions. However, this raises the question, whether there is such a thing as being too aware of a hazard.

The past couple of decades have seen significant levels of research on risk perception and the factors that influence it (Slovic et al. 1984; Nighswonger Kraus and Slovic 1988; Renn 1998; Sjöberg 2000). Many of these factors can be traced back to psychological biases and cultural context. One factor is the level of awareness of and knowledge about a hazard. This can be expressed in several ways, including: whether the risk is known or unknown (Slovic et al. 1984; Nighswonger Kraus and Slovic 1988); whether the risk is new or old (Sjöberg 2000); and the level of 
Table 8 Distribution of answers from local residents and public officials regarding suggestions for improvements in the Akuressa area of Sri Lanka

\begin{tabular}{lcc}
\hline Response to floods & Number of residents & Number of officials \\
\hline Structural improvements & 37 & 4 \\
Nonstructural improvements & 7 & 4 \\
Don't know & 3 & \\
Nothing can be done & 1 & \\
\hline
\end{tabular}

familiarity with the risk (Renn 1998), also referred to as "habituation" (Lima 2004). There seems to be a consensus that awareness of and knowledge about a hazard affects how the risk associated with it is perceived. This is considered natural, since increased knowledge about a hazard includes increased knowledge about the likelihood and potential consequences related to it. However, this does not seem to apply to personal risk perception, where increased awareness and knowledge do not necessarily lead a person to consider him/herself at greater risk, even if the evidence suggests they should. The popular expression "people fear what they do not understand" is fitting in this context and has proven accurate on many occasions. Whether people feel less afraid of what they do understand depends on the knowledge they gain. This study suggests that flood awareness lowers the risk perception of local residents, although experience and knowledge have made them aware of the potentially devastating consequences. This notion is supported by earlier work. Renn (1998) argued that familiarity with a risk is likely to increase tolerance for it, while Slovic et al. (1984) found a correlation with hazards rated as "well known" and "controllable."

This raises the question of how it is possible that increased awareness of and knowledge about a hazard can result in lower risk perception. Our findings make it clear that floods are a part of everyday life for local residents, particularly the majority of long-term residents. Flood risk is normalized. It is not shrouded in clouds of uncertainty, which appears to remove much of the associated worry and fear. Although this situation has its roots in years of adaptation and ability to cope with the hazard, it can also pose a serious threat for the future.

"Positive illusion" is a psychological bias often associated with a decrease in personal risk perception. It can be explained as a coping strategy that individuals use to have a sense of control over something that is in fact uncontrollable, and often results in a false sense of security (Johnson and Levin 2009; Luìs et al. 2016). This can contribute to increased vulnerability by compromising preparedness efforts. Johnson and Levin (2009) highlighted that positive illusions can disappear once an individual is directly affected by the hazard in question, and the risk is no longer hypothetical, but real. However, this does not apply in the current study, because all respondents have experienced several floods, suggesting that positive illusions can persist regardless of personal experience with the actual hazard. In many cases, the sense of confidence in one's ability to manage the situation is justified when it comes to managing the annual, small to medium-sized floods. However, it is less realistic when coping with bigger floods, such as those of 2003.

One outcome of normalizing flood risks, whether through experience and adaptation, or cognitive biases, is a decrease in worry. Could this lack of concern be the missing link between risk awareness and risk perception? Someone who is concerned about flood risk is more inclined to take action to reduce their exposure (Raaijmakers et al. 2008). However, it appears that worry is not enough to implement risk reduction measures if there are real or perceived constraints on change. The contrary appears more logical: someone who is not worried about risk is unlikely to see a reason to take risk reduction measures. Earlier research has established that the more we are exposed to something, the more familiar it gets, and the more we tend to develop a higher tolerance for it (Becker 2014). This is referred to as the "familiarity principle" (Politz 1960), or the "exposure effect" (Zajonc 1968), and seems to provide at least a partial explanation for the high risk awareness, but low risk perception found in this study.

Our findings indicate that many local residents seem to be prepared for, and are confident in their ability to manage, annual small to moderate floods-regardless of their detrimental effect on health, education, livelihoods, and so on. However, coping with a major flood, such as the 2003 event, is an entirely different question. It is clear that any campaign to increase community preparedness must address the normalization of risk, if the campaign is to have any effect. One way to achieve this may be to emphasize the harsh reality of the situation. For example, it is likely that climate change will make future floods both more frequent and worse. The 2003 flood could be used to demonstrate the future normal. 


\subsection{Risk Trade-Offs}

All humans evaluate risk on a daily basis, either consciously or subconsciously. All respondents mentioned floods as a downside of where they lived, and everyone had experienced the consequences of seasonal floods firsthand. It is easy to assume that the people living in these areas would like to move somewhere else. However, that does not appear to be the case. Despite their awareness of the flood risk, many respondents do not wish to move. This attitude appears to be partly due to a belief that the benefits of living in the Akuressa area outweigh the risks. The existence of such trade-offs is backed by well-established literature (Burton et al. 1968; Fischhoff et al. 1978; Raaijmakers et al. 2008). Individuals perceive risk as either acceptably low, or too high. However, what is acceptable cannot be determined in isolation, as tolerance is closely related to the perceived benefits associated with living in a place in spite of risk exposure. A perceived high level of risk can be acceptable if the perceived benefits are large enough. In this study, urban residents value public services, because these services are readily accessible. Rural residents value cultivation, because farming is a central part of rural life.

Applying the notion of risk trade-offs to our context, it appears to be applicable in many cases. First, there are those who clearly expressed an unwillingness to move. The many perceived benefits mean that they prefer to stay in the area despite the flood risk. Second, others expressed a willingness to move, but only to a comparable location. In this case, they appeared reluctant to trade the benefits of the area for a lower risk exposure.

It is clear that the normalization of risk plays an important role in this trade-off. This is therefore an important element to consider when engaging in risk reduction or preparedness activities. Oversimplified and incorrect assumptions about the situation of those living in high-risk areas may lead to ineffective solutions (OliverSmith 1991).

\subsection{Pulling or Pushing Back}

Most people can relate to the idea of a "sense of place"; the typical example is a special attachment to the childhood home (Chawla 1992). Some respondents expressed their close ties to the area, particularly in the form of generational links. Family history often played a big role, either because the house and land had been inherited through the generations, or because other family members were living nearby. Respondents also expressed a strong connection to the geographical location and community. Many identified with the surrounding areas, where they were either born or had spent a substantial part of their life, and which they considered home.

There is a substantial body of research on sense of place (for example, Twigger-Ross and Uzzell 1996) and its role in risk perception (for example, Wester-Herber 2004). Bonaiuto et al. (2016) reviewed 31 studies and identified some general trends regarding the effect of sense of place on, for instance, risk perception and risk coping. The review concluded that individuals with a strong sense of place tend to have a well-developed awareness of the risks associated with the area. At the same time, in many cases, a strong sense of place appears to result in low risk perception leading to poor coping mechanisms. This is consistent with our findings - the local residents of the Akuressa area are well aware of the flood risk situation, but at the same time make little effort to prepare. The literature provides no insight into why this is the case, and more research is needed. It could be a simple coping mechanism. One hypothesis is that an individual with a close personal bond to an area, who does not believe that they can find a better alternative, subconsciously underestimates the risks of their current location. This would explain both their decision to stay, and to minimize any stress and worry associated with living in a flood-prone area. Another interesting feature of disaster-prone areas is a particularly strong sense of community (Cox and Perry 2011). Residents are often eager to return to their community as soon as possible after a destructive event, to begin rebuilding and return to normal. People come together to help each other, and the sense of community is strengthened (Silver and Grek-Martin 2015). This, combined with a strong sense of place and strong links to the community, may increase the unwillingness to relocate. The effect is more apparent in areas such as Akuressa, because each year the community gathers together to respond to floods. They are pulled back by a sense of place and belonging.

Although many respondents wish to stay, others express a willingness to move, but give various reasons for why they find it is difficult to do so. Renting is uncommon, even more so in rural areas. Most homes are owner-occupied and land is attached to the property. This results in a static housing system, as the current place of residence is an investment. Moving in general appeared to be an unfamiliar idea for the respondents. Even those who expressed a willingness to move were unclear about how to go about it. Similar arguments apply to those who were prepared to move to an equivalent location. In some cases, some family members were willing to move, but others wanted to stay. Family bonds are particularly strong when the family provides a form of social security. Last but not least, financial constraints played a part. Only male respondents mentioned them, which is consistent with the idea that men are mostly responsible for the household income. This 
gender difference in mentioned constraints is likely based more on gendered differences in control over financial resources, than on differences in actual financial resources. Women are not less financially constrained just because they did not mention financial constraints in the interviews. It is more likely they did not mention financial constraints because these are outside their sphere of influence. In sum, various constraints contribute to pushing residents back to their current homes. Another interesting finding is that rural respondents seem to think that it is more difficult to move than urban respondents. The results provide no immediate explanation for this. One factor could be that urban dwellers do not depend on their land to the same extent as rural residents do. Another factor could be tradition. Rural families who have lived in the same area for generations could see relocation as more complicated. Urban residents are more likely to be part of a family who has already taken part in the urbanization process; therefore, they already have relocation experience.

It is fair to assume that most people would be willing to move if offered an equivalent, flood-free, location. In many ways, this is equivalent to saying, "I'd rather not be exposed to floods." At the same time, nobody appeared to be forced to live in the area. Therefore, to some extent, residents have chosen their current location, although their decision might be based on structural constraints and a lack of better alternatives. This is closely related to White's (1964) seminal notion of range of choice, with the theoretical range of choice being set by the physical environment and available technology, while the practical range of choice is also determined by culture and institutions. An interesting avenue for future work would be to interview people who have made the decision to leave.

\subsection{Government-Community Disconnect}

The importance of being aware of the local context and ensuring that risk reduction measures are locally rooted has been well documented (Quarantelli 1997; Perry and Lindell 2003; UNDP 2004; Coppola 2011; Becker 2014). However, the establishment of safe places in the Akuressa area by the government appears to demonstrate a clear mismatch between resources and the actual needs of the target group. Government officials considered that the initiative was successful and believed that most people evacuated to these locations. Local residents emphasized that most people went to stay with family or friends, rather than go to official safe places. There are two, interconnected, reasons for this. First, it is clear that family values are strong and most respondents live close to other family members. In many cases, these people live in a safer area that is easier to reach than a government-run safe place. Second, residents are more likely to seek support from people they know than government officials, or other strangers. Going to stay with a family member or friend offers more than physical safety-it also provides social and emotional support.

The sample size of our study was not large enough to draw any statistically valid conclusions regarding how many people use official safe places. However, if our findings can be extended to the broader population, government-run safe places appear to be an example of misdirected resources. No information was collected regarding the cost of establishing and maintaining the safe places. Opening up schools and temples might not require a big monetary investment, but could disrupt education and the social fabric.

\section{Conclusion}

So, why do people live in flood-prone areas around Akuressa, Sri Lanka? Our study has shown that this is a very complex question to answer fully. However, our findings suggest there are four main reasons: (1) overall good living situation; (2) sense of place; (3) difficulties relocating; and (4) being well-adapted to the situation. Although this may indicate that recurrent flooding is not a problem, the reality is that our results testify to the immense fortitude and adaptability of the residents. However, the frequency and impact of flooding means that it is of fundamental importance to explain and understand the underlying processes.

The first is risk normalization, by which long-term, recurrent exposure increases flood awareness, but decreases aversion through a combination of previous experience and cognitive bias. This process erodes residents' motivation to engage in activities and make adjustments that reduce risk and increase preparedness. The second is risk trade-off, in which the perceived benefits of living in the area outweigh the perceived problem of recurrent, low to medium intensity floods. Combined with risk normalization this process leads to increased risk taking and undermines the potential to anticipate and adapt to an escalating flood risk resulting from climate change, and other global changes. Finally, there is a set of pull-and-push processes. These carrots and sticks represent pressures that maintain the status quo. Pull processes include social processes that not only keep people in high-risk locations, but also provide the primary bulwark against adversity. Push processes refer to socioeconomic processes that determine the structural constraints that limit opportunities. Any effective risk reduction or preparedness activities must be based on an understanding of these underlying processes, and the perspective of the local community. 
Open Access This article is distributed under the terms of the Creative Commons Attribution 4.0 International License (http://crea tivecommons.org/licenses/by/4.0/), which permits unrestricted use, distribution, and reproduction in any medium, provided you give appropriate credit to the original author(s) and the source, provide a link to the Creative Commons license, and indicate if changes were made.

\section{References}

Adger, N.W. 2006. Vulnerability. Global Environmental Change 16: 268-281.

Becker, P. 2014. Sustainability science: Managing risk and resilience for sustainable development. Amsterdam: Elsevier.

Bernard, R.H. 2006. Research methods in anthropology: Qualitative and quantitative approaches. Oxford: Rowman \& Littlefield.

Bonaiuto, M., S. Alves, S. De Dominicis, and I. Petruccelli. 2016. Place attachment and natural hazard risk: Research review and agenda. Journal of Environmental Psychology 48: 33-53.

Burton, I., R.W. Kates, and G.F. White. 1968. The human ecology of extreme geophysical events. Natural hazard research working paper No.1. Tampa, FL: Louis de la Parte Florida Mental Health Institute.

Burton, I., R.W. Kates, and G.F. White. 1978. The environment as hazard. Oxford and New York: Oxford University Press.

Charmaz, K. 2006. Constructing grounded theory: A practical guide through qualitative analysis. London: SAGE Publications.

Chawla, L. 1992. Childhood place attachments. In Place attachment, ed. I. Altman, and S.M. Low, 63-86. New York: Springer US.

Coppola, D.P. 2011. Introduction to international disaster management, 2nd edn. Burlington, MA: Butterworth-Heinemann.

Cox, R.S., and K.-M.E. Perry. 2011. Like a fish out of water: Reconsidering disaster recovery and the role of place and social capital in community disaster resilience. American Journal of Community Psychology 48(3-4): 395-411.

CRED (Center for Research on the Epidemiology of Disasters). 2016. EM-DAT: The international disasters database. http://www. emdat.be. Accessed 9 Dec 2016.

Fischhoff, B., P. Slovic, and S. Lichtenstein. 1978. How safe is safe enough? A psychometric study of attitudes towards technological risks and benefits. Policy Sciences 9(2): 127-152.

Freed, A. 1988. Interviewing through an interpreter. Social Work 33(4): 315-319.

Hearn Morrow, B. 1999. Identifying and mapping community vulnerability. Disasters 23(1): 1-18.

Hewitt, K. 1983. The idea of calamity in a technocratic age. In Interpretations of calamity, ed. K. Hewitt, 3-32. London and Winchester: Allen \& Unwin.

Höst, M., B. Regnell, and P. Runeson. 2006. To complete the degree project (Att genomföra examensarbete). Lund: Studentlitteratur (in Swedish).

Johnson, D., and S. Levin. 2009. The tragedy of cognition: Psychological biases and environmental inaction. Current Science 97(11): 1593-1603.

Kates, R.W. 1976. Experiencing the environment as hazard. New York and London: Plenum Press.

Lima, M.L. 2004. On the influence of risk perception on mental health: Living near an incinerator. Journal of Environmental Psychology 24(1): 71-84.

Longhurst, R. 2016. Semi-structured interviews and focus groups. In Key methods in geography, ed. R. Rojek, 143-156. London: SAGE Publications.

Luìs, S., L. Pinho, M. Lima, C. Roseta-Palma, F. Cardoso Martins, and A. de Almeida. 2016. Is it all about awareness? The normalization of coastal risk. Journal of Risk Research 19(6): $810-826$.

McEntire, D.A. 2005. Why vulnerability matters: Exploring the merit of an inclusive disaster reduction concept. Disaster Prevention and Management 14(2): 206-222.

Ministry of Disaster Management Sri Lanka. 2012. Hazard profiles of Sri Lanka. Colombo: Nanila Publication (Pvt). http://www.dmc. gov.lk/hazard/hazard/Report.html. Accessed 3 Oct 2016.

Ministry of Policy Planning and Economic Affairs. 2012. Census of population and housing 2012. Department of Census and Statistics. Battaramulla: Ministry of Policy Planning and Economic Affairs.

Nighswonger Kraus, N., and P. Slovic. 1988. Taxonomic analysis of perceived risk: Modeling individual and group perceptions within homogeneous hazard domains. Risk Analysis 8(3): 435-455.

O'Keefe, P., K. Westgate, and B. Wisner. 1976. Taking the naturalness out of natural disasters. Nature 260: 566-567.

Oliver-Smith, A. 1991. Successes and failures in post-disaster resettlement. Disasters 15(1): 12-23.

Perry, R.W., and M.K. Lindell. 2003. Preparedness for emergency response: Guidelines for the emergency planning process. Disasters 27(4): 336-350.

Politz, A. 1960. The dilemma of creative advertising. Journal of Marketing 25(2): 1-6.

Quarantelli, E. 1997. Ten criteria for evaluating the management of community disasters. Disasters 21(1): 39-56.

Raaijmakers, R., J. Krywkow, and A. van der Veen. 2008. Flood risk perceptions and spatial multi-criteria analysis: An exploratory research for hazard mitigation. Natural Hazards 46(3): 307-322.

Renn, O. 1998. The role of risk perception for risk management. Reliability Engineering and System Safety 59(1): 49-62.

Scolobig, A., B. De Marchi, and M. Borga. 2012. The missing link between flood risk awareness and preparedness: Findings from case studies in an Alpine Region. Natural Hazards 63(2): 499-520.

Silver, A., and J. Grek-Martin. 2015. "Now we understand what community really means": Reconceptualizing the role of sense of place in the disaster recovery process. Journal of Environmental Psychology 42: 32-41.

Sjöberg, L. 2000. Factors in risk perception. Risk Analysis 20(1): $1-11$.

Slovic, P. 2001. The risk game. Journal of Hazardous Materials 86: $17-24$.

Slovic, P., B. Fischhoff, and S. Lichtenstein. 1984. Behavioral decision theory perspectives on risk and safety. Acta Psychologica 56(1-3): 183-203.

Smith, K. 2013. Environmental hazards: Assessing risk and reducing disaster, 6th edn. New York: Routledge.

Sooriyabandara, L. 2016. Chief irrigation engineer at the district irrigation department. Interview by O. Nilsson, and J. Askman, 9 September 2016, Matara, Sri Lanka.

Turner II, B.L., R.E. Kasperson, P.A. Matson, J.J. McCarthy, R.W. Corell, L. Christensen, A. Schiller. 2003. A framework for vulnerability analysis in sustainability science. Proceedings of the National Academy of Science 100(14): 8074-8079.

Twigger-Ross, C.L., and D.L. Uzzell. 1996. Place and identity processes. Journal of Environmental Psychology 16: 205-220.

UNDP (United Nations Development Programme). 2004. Reducing disaster risk: A challenge for development. New York: UNDP.

Wester-Herber, M. 2004. Underlying concerns in land-use conflicts: The role of place-identity in risk perception. Environmental Science and Policy 7(2): 109-116.

White, G.F. 1945. Human adjustment to floods: A geographical approach to the flood problem in the United States. University of Chicago, Department of Geography, Research Paper No. 29. 
White, G.F. 1964. Choice of adjustment to floods. University of Chicago, Department of Geography, Research Paper No. 93.

Wisner, B., P. Blaikie, T. Cannon, and I. Davis. 2003. At risk: Natural hazards, people's vulnerability and disasters. New York: Routledge.

Yin, R.K. 2002. Case study research: Design and methods, 3rd edn. Thousand Oaks, CA: SAGE Publications.
Zajonc, R.B. 1968. Attitudinal effects of mere exposure. Journal of Personality and Social Psychology 9(2): 1.

Zubair, L. 2004. May 2003 disaster in Sri Lanka and cyclone 01-B in the bay of Bengal. Natural Hazards 33(3): 303-318. 